\title{
Transfusion in trauma: thromboelastometry-guided coagulation factor concentrate-based therapy versus standard fresh frozen plasma-based therapy
}

\author{
Herbert Schöchl ${ }^{1,2}$, Ulrike Nienaber ${ }^{3}$, Marc Maegele ${ }^{4}$, Gerald Hochleitner ${ }^{5}$, Florian Primavesi ${ }^{2}$, Beatrice Steitz ${ }^{6}$, \\ Christian Arndt ${ }^{7}$, Alexander Hanke ${ }^{8}$, Wolfgang Voelckel ${ }^{2}$ and Cristina Solomon ${ }^{6 *}$
}

\begin{abstract}
Introduction: Thromboelastometry (TEM)-guided haemostatic therapy with fibrinogen concentrate and prothrombin complex concentrate (PCC) in trauma patients may reduce the need for transfusion of red blood cells (RBC) or platelet concentrate, compared with fresh frozen plasma (FFP)-based haemostatic therapy.

Methods: This retrospective analysis compared patients from the Salzburg Trauma Centre (Salzburg, Austria) treated with fibrinogen concentrate and/or PCC, but no FFP (fibrinogen-PCC group, $n=80$ ), and patients from the TraumaRegister DGU receiving $\geq 2$ units of FFP, but no fibrinogen concentrate/PCC (FFP group, $n=601$ ). Inclusion criteria were: age 18-70 years, base deficit at admission $\geq 2 \mathrm{mmol} / \mathrm{L}$, injury severity score (ISS) $\geq 16$, abbreviated injury scale for thorax and/or abdomen and/or extremity $\geq 3$, and for head/neck $<5$.

Results: For haemostatic therapy in the emergency room and during surgery, the FFP group (ISS $35.5 \pm 10.5$ ) received a median of 6 units of FFP (range: 2, 51), while the fibrinogen-PCC group (ISS $35.2 \pm 12.5$ ) received medians of $6 \mathrm{~g}$ of fibrinogen concentrate (range: 0,15 ) and $1200 \mathrm{U}$ of PCC (range: 0,6600 ). RBC transfusion was avoided in $29 \%$ of patients in the fibrinogen-PCC group compared with only $3 \%$ in the FFP group $(P<0.001)$. Transfusion of platelet concentrate was avoided in $91 \%$ of patients in the fibrinogen-PCC group, compared with $56 \%$ in the FFP group $(P<0.001)$. Mortality was comparable between groups: $7.5 \%$ in the fibrinogen-PCC group and $10.0 \%$ in the FFP group $(P=0.69)$.
\end{abstract}

Conclusions: TEM-guided haemostatic therapy with fibrinogen concentrate and PCC reduced the exposure of trauma patients to allogeneic blood products.

\section{Introduction}

In patients with severe trauma, coagulopathy represents a frequent cause of death $[1,2]$. Prompt haemostatic intervention is necessary to prevent and correct lifethreatening bleeding. Standard coagulation therapy consists of fresh frozen plasma (FFP), platelet concentrate and, in some countries, cryoprecipitate $[3,4]$. One approach proposed for preventing exsanguination has been to treat patients with a fixed ratio of FFP to red blood cells (RBC), but the optimal value of this ratio is still under debate [5-8]. It has been recently suggested

\footnotetext{
* Correspondence: Solomon.Cristina@googlemail.com

${ }^{6}$ Department of Anaesthesiology and Intensive Care, Salzburger

Landeskliniken SALK, Müllner Hauptstrasse 48, A-5020 Salzburg, Austria

Full list of author information is available at the end of the article
}

that the time to intervention may also be an important determinant of patient outcomes $[9,10]$.

Our group has been exploring goal-directed coagulation management using fibrinogen concentrate and prothrombin complex concentrate (PCC), administered as early as possible according to thromboelastometric (TEM) measurements $[11,12]$. This approach supports timely and aggressive correction of coagulopathy. It may also be considered as a strategy for reducing transfusion of allogeneic blood products: the need for FFP may be reduced by the administration of coagulation factors: fibrinogen, contained in fibrinogen concentrate, and factors II, VII, IX and X, contained in most PCCs. Furthermore, clinical and experimental data suggest that fibrinogen supplementation may also compensate for

\section{Biomed Central}

(C) 2011 Schöchl et al.; licensee BioMed Central Ltd. This is an open access article distributed under the terms of the Creative Commons Attribution License (http://creativecommons.org/licenses/by/2.0), which permits unrestricted use, distribution, and reproduction in any medium, provided the original work is properly cited 
reduced platelet count $[13,14]$. Supplementation of fibrinogen may support primary haemostasis, because fibrinogen facilitates platelet aggregation by bridging platelet glycoprotein IIb/IIIa receptors [15]. In addition, the use of fibrinogen concentrate leads to increased firmness of the fibrin-based clot [16], whereas PCC administration may correct prolonged coagulation times through improved thrombin generation [17].

We recently reported favourable outcomes in major trauma patients referred to our level 1 trauma centre and treated following TEM-guided haemostatic therapy with fibrinogen concentrate and PCC [12]. Observed mortality in this retrospective analysis was lower than that predicted by the Revised Injury Severity Classification Score (RISC) [18] and Trauma Injury Severity Score (TRISS) [19]. The treatment strategy eliminated time delays associated with standard coagulation testing and preparation of allogeneic blood products for transfusion: more than half of the patients received haemostatic therapy within an hour of admission to the emergency room (ER). Furthermore, the low transfusion rates suggested that TEM-guided haemostatic therapy with fibrinogen concentrate and PCC may reduce the use of allogeneic blood products in trauma patients.

In the present retrospective study, we compared two different concepts of haemostatic therapy in major trauma patients: TEM-guided haemostatic therapy with fibrinogen concentrate and PCC versus FFP-based therapy. Patients receiving coagulation factor concentrates were treated at the Salzburg Trauma Centre (STC; Salzburg, Austria). Those receiving FFP-based therapy were selected from the trauma registry of the German Society for Trauma Surgery (TR-DGU), which includes 161 trauma hospitals, mostly in Germany, and holds details of a very large number of patients treated with standard coagulation therapy. We hypothesised that transfusion of RBC and platelet concentrate is lower in patients receiving TEM-guided haemostatic therapy with fibrinogen concentrate and PCC, compared with patients receiving FFP-based therapy.

We hypothesised that TEM-guided haemostatic therapy with fibrinogen concentrate and PCC may lead to increased avoidance of $\mathrm{RBC}$ and platelet concentrate transfusion compared with FFP-based therapy.

\section{Materials and methods}

Fibrinogen-PCC group (Salzburg Trauma Centre)

Following local ethics committee approval, we performed a retrospective analysis of transfusion parameters in major trauma patients who were admitted to the STC from 2006 to 2009 and treated with fibrinogen concentrate and PCC according to TEM ${ }^{\circledR}$ analyses, performed using ROTEM $^{\circledR}$ (Tem International, Munich, Germany) as previously described by Schöchl et al [12]. Demographic data, laboratory data, trauma scores and outcomes data were obtained from the electronic database that was used for recording ER therapy and from the ICU database.

\section{FFP group (TR-DGU)}

The TR-DGU is a repository for prospective, standardised and anonymous documentation of data on severely injured patients requiring ICU treatment [6]. At the beginning of 2010, TR-DGU contained data from more than 42,000 patients. Patients treated between 2005 and 2008 were included in the present study. As described elsewhere [6], the registry includes information on demographics, injury severity and pattern, preand in-hospital management, laboratory findings, time course and the outcome for each patient.

\section{Inclusion and exclusion criteria}

Inclusion criteria for both groups of patients were: age between 18 and 70 years, injury severity score (ISS) of 16 or more, base deficit at admission or $2 \mathrm{mmol} / \mathrm{L}$ or higher, abbreviated injury scale (AIS) for thorax and/or abdomen and/or extremity of 3 or more and AIS for head/neck less than 5 (Table 1). Furthermore, only patients with all information needed to calculate TRISS and RISC scores were included.

For the fibrinogen-PCC group, patients who received fibrinogen $(\geq 1 \mathrm{~g})$ and/or PCC ( $\geq 500 \mathrm{U})$ but no FFP were included. For the FFP group, patients who received at least 2 units of FFP but no fibrinogen concentrate or PCC were included.

\section{Coagulation management}

In the fibrinogen-PCC group, coagulation management was guided by TEM analysis [12]. Haemostatic therapy comprised administration of 2 to $4 \mathrm{~g}$ of fibrinogen concentrate (first-line therapy for patients needing increased firmness of the fibrin-based clot), and administration of 1,000 to $1,500 \mathrm{U}$ of PCC, for patients showing prolonged clotting time in the thromboelastometry EXTEM test (> 1.5 times normal) [12]. This treatment was repeated as necessary. Fibrinogen concentrate was administered using two to four automatic infusion systems (Perfusor $^{\circledR}$, B. Braun, Melsungen, Germany) working in parallel, each at a rate of $200 \mathrm{~mL} / \mathrm{h}$; for each infusion system, $1 \mathrm{~g}$ of fibrinogen concentrate was diluted in 50 $\mathrm{mL}$ of water for injections. The resulting administration rate was 2 to $4 \mathrm{~g}$ in 15 minutes. For patients in whom fibrinogen could not fully compensate for decreased platelet levels, platelet concentrate was transfused (platelet concentrate was recommended if the EXTEM-MCF is decreased to $<40 \mathrm{~mm}$ when FIBTEM-MCF is 10 to 12 $\mathrm{mm})$. The target haemoglobin concentration during the operative procedure was $10 \mathrm{~g} / \mathrm{dL}$. In the postoperative phase, lower haemoglobin levels were tolerated. 
Table 1 Inclusion criteria

\begin{tabular}{|c|c|c|}
\hline & $\begin{array}{c}\text { Fibrinogen-PCC group } \\
\text { (Salzburg Trauma Centre) }\end{array}$ & FFP group (TR-DGU) \\
\hline Type of therapy & ROTEM-guided administration of coagulation factor concentrates & According to local protocols \\
\hline ISS & \multicolumn{2}{|l|}{$\geq 16$} \\
\hline AIS thorax, abdomen, extremities & \multicolumn{2}{|c|}{ At least in one region, one injury with severity degree $\geq 3, \mathrm{AlS}_{\text {head } / \text { neck }}<5$} \\
\hline Age (years) & \multicolumn{2}{|l|}{$18-70$} \\
\hline Base deficit at admission & \multicolumn{2}{|l|}{$\geq 2 \mathrm{mmol} / \mathrm{L}$} \\
\hline FFP administered & No FFP & $\geq 2$ units FFP \\
\hline Fibrinogen/PCC administered & $\geq 1$ g fibrinogen; $\geq 500 \cup$ PCC & No fibrinogen or PCC \\
\hline Investigated time period & $2005-2009$ & $2005-2008$ \\
\hline Patients included in database & 353 & 21263 \\
\hline Patients fulfilling inclusion criteria & 80 & 601 \\
\hline
\end{tabular}

AIS, abbreviated injury scale; FFP, fresh frozen plasma; ISS, injury severity score; $n$, number of patients; PCC, prothrombin complex concentrate; ROTEM, thromboelastometry; TR-DGU, trauma registry of the German Society for Trauma Surgery.

Coagulation management of patients in the FFP group was dictated by clinical practice at each trauma department and was therefore not standardised. TEM is not used in standard practice; nevertheless, isolated use in some hospitals means that a minority of patients in the registry may have been treated with some TEM guidance. Although the treatment of patients in the TRDGU is not standardised, it represents the general approach to coagulation management of major trauma patients in Germany, with FFP administered as first-line haemostatic therapy, and platelet concentrate and $\mathrm{RBC}$ used as necessary. Laboratory analyses of coagulation were performed in the local laboratories; the register collects no information on the type of analyses, reagents or devices on which they are performed, or on their role in guiding haemostatic therapy within the local protocol.

\section{Selection of variables for analysis}

For all subjects, age and gender were documented together with the following parameters upon admission: coagulation results, blood pressure, heart rate, temperature, ISS and Glasgow coma scale score. Predicted mortality for each patient was estimated using the RISC and the TRISS methodology. Mortality rate (until discharge from the hospital) was documented.

Details of coagulation management were noted for the acute phase (ER and early surgery phase) and the first 48 hours spent in the ICU. For the fibrinogen-PCC group, administration of RBC, fibrinogen concentrate, PCC and platelet concentrate were noted for both time periods. For the FFP group, administration of RBC and FFP were noted for both time periods; data for platelet concentrate administration were only available for the acute phase.

\section{Statistical analysis}

Demographic and clinical data were presented as mean \pm standard deviation or median (minimum, maximum or interquartile range (IQR), as indicated) for continuous variables, and as percentages for categorical variables. For continuous variables, normal distribution was analysed by the Shapiro-Wilk test. To detect differences between the patient groups, either the Student's $t$-test or the Mann-Whitney $U$ test was performed, depending on the underlying distribution. For categorical variables, Fisher's exact test was used. Statistics were calculated using IBM SPSS Statistics 18 (SPSS Inc., Chicago, IL, USA).

\section{Results}

In the fibrinogen-PCC group, 80 of 353 patients treated in the STC between 2005 and 2009 fulfilled the inclusion criteria. Between 2005 and 2008 (data for 2009 were not available at the time of analysis), 21,263 patients were included in the TR-DGU. Of 21,263 patients, 2,582 fulfilled the general inclusion criteria. At this step, most cases were lost due to missing base deficit values. After applying the specific haemostatic therapy criteria (Table 1), 601 patients could be included in the FFP group.

Demographic data and trauma scores were available for all patients included in the study. As intended, the two groups were comparable with regard to demographic parameters as well as the overall magnitude of injury sustained and probability of survival assessed by the TRISS and RISC scores (Table 2). With regard to the pattern of injury, patients in the FFP group had sustained head and thoracic injuries of higher magnitude, whereas fibrinogen-PCC patients had sustained more severe abdominal injuries. Patients in the fibrinogenPCC group also appeared to be less haemodynamically stable upon arrival at the ER. Standard laboratory coagulation data were available for at least $90 \%$ of the patients included in the study. A significantly more prolonged prothrombin time (PT) was observed in the fibrinogen-PCC group $(P=0.0001$; Table 3$)$; this difference 
Table 2 Patient demographic and clinical data

\begin{tabular}{lcc}
\hline & Fibrinogen-PCC group $(\boldsymbol{n}=\mathbf{8 0})$ & FFP group $(\boldsymbol{n}=\mathbf{6 0 1})$ \\
\hline Age (years) & $37.3 \pm 14.5$ & $39.1 \pm 14.5$ \\
Male $n$ (\%) & $63(79)$ & $442(74)$ \\
Systolic blood pressure on admission at ER (mmHg) & $95 \pm 30$ & $108 \pm 30^{* *}$ \\
Heart rate on admission at ER (beats/minute) & $105 \pm 26$ & $99 \pm 24^{*}$ \\
ISS & $35.5 \pm 10.5$ & $35.2 \pm 12.5$ \\
GCS & $12.2 \pm 3.4$ & $11.3 \pm 4.4^{*}$ \\
AIS Head & $1.1 \pm 1.5$ & $1.6 \pm 1.7^{*}$ \\
AIS Chest & $2.1 \pm 2.0$ & $3.1 \pm 1.7^{* *}$ \\
AIS Abdomen & $2.5 \pm 2.1$ & $2.1 \pm 1.8$ \\
AIS Extremity & $2.9 \pm 1.8$ & $2.9 \pm 1.4$ \\
TASH & $13.9 \pm 6$ & $12.6 \pm 5^{*}$ \\
RISC & $6.9(2.4,16.2)$ & $8.5(3.3,24.8)$ \\
TRISS & $13(3,38)$ & $7(2,38)$ \\
Death & $6(7.5)$ & $60(10)$ \\
\hline
\end{tabular}

Data are presented as mean \pm standard deviation, median (interquartile range) or as absolute and relative frequency.

${ }^{*} P<0.05$, significantly different than the fibrinogen-PCC group;

**P $=0.0001$, significantly different than the fibrinogen-PCC group.

AIS, abbreviated injury score; ER, emergency room; FFP, fresh frozen plasma; n, number of patients; GCS, Glasgow coma scale; ISS, injury severity score; PCC, prothrombin complex concentrate; RISC, revised injury severity classification; TASH, trauma associated severe haemorrhage score; TRISS, trauma injury severity score.

was apparent upon arrival at the ICU as well as the ER. The base deficit also differed between the groups $(6.4 \pm$ 3.4 in the fibrinogen-PCC group and $6.9 \pm 4.5 \mathrm{mmol} / \mathrm{L}$ in the FFP group), but this difference did not reach statistical significance.

$\mathrm{RBC}$ transfusion data for treatment in the ER and during surgery were available for all patients. Complete avoidance of RBC transfusion was observed in 3\% of patients in the FFP group and $29 \%$ of patients in the fibrinogen-PCC group ( $P<0.0001$; Figure 1$)$. In the FFP group, 583 of 601 patients (97\%) received RBC transfusion (number of units ranging between 1 and 64), compared with 57 of 80 patients $(71 \%)$ in the fibrinogenPCC group (range: 1 to 28 units). Information on platelet concentrate transfusion for treatment in the ER and during surgery was available for 371 of the 601 patients in the FFP group, and for all patients in the fibrinogenPCC group. Platelet concentrate was administered to $44 \%$ of patients in the FFP group, compared with $9 \%$ in the fibrinogen-PCC group $(P=0.0001$; Figure 1$)$. Of interest, all patients with no transfusion of RBC also did not receive any platelet concentrate, meaning total avoidance of allogeneic blood products in $29 \%$ of the patients in the fibrinogen-PCC group.

For haemostatic therapy in the ER and during surgery, the FFP group received a median of 6 units of FFP (IQR: 4, 10; range: 2, 51), 6 units of RBC (IQR: 4, 11) and 0 units of platelet concentrate (IQR: 0,2 ; range: 0 , 8). The patients in the fibrinogen-PCC group received a median of $6 \mathrm{~g}$ of fibrinogen concentrate (IQR: 3, 9; range: 0,15$)$ and $1,200 \mathrm{IU}$ of PCC (IQR: 0, 2,400; range: $0,6,600)$, while $\mathrm{RBC}$ median transfusion was 5.5 units (IQR: 0, 9.5) and platelet concentrate median transfusion was 0 units (IQR: 0, 0; range: 0,2 ). The dosage of FFP, fibrinogen and PCC is described in Figure 2. During the first 48 hours after admission to the ICU, patients in the FFP group received median doses of 3 units of RBC (IQR: 1, 6; range: 0, 80; data reported for

Table 3 Standard laboratory parameters

\begin{tabular}{lcccc}
\hline & \multicolumn{2}{c}{ Admission in the emergency room } & \multicolumn{2}{c}{ Arrival at the ICU } \\
\cline { 2 - 5 } & $\begin{array}{r}\text { Fibrinogen-PCC group } \\
(n=80)\end{array}$ & $\begin{array}{c}\text { FFP group } \\
(n=601)\end{array}$ & $\begin{array}{c}\text { Fibrinogen-PCC group } \\
(n=80)\end{array}$ & $\begin{array}{c}\text { FFP group } \\
(n=601)\end{array}$ \\
\hline Haemoglobin $(13.5-17 \mathrm{~g} / \mathrm{dL})$ & $9.9 \pm 3.1$ & $9.6 \pm 2.6$ & $9.6 \pm 2.1$ & $9.7 \pm 1.9$ \\
Platelet count $(150-350 * 1000 \mathrm{cell} / \mathrm{sL})$ & $178 \pm 68$ & $184 \pm 79$ & $105 \pm 58$ & $108 \pm 60$ \\
$\begin{array}{l}\text { Prothrombin time in percentage } \\
\text { (70-110\%) }\end{array}$ & $59 \pm 19$ & $65 \pm 21^{*}$ & $52 \pm 16$ & $71 \pm 18^{* *}$ \\
Fibrinogen $(2-4.5 \mathrm{~g} / \mathrm{L})$ & $1.4 \pm 0.7$ & not available & $1.8 \pm 0.5$ & not available \\
\hline
\end{tabular}

Data are presented as mean \pm standard deviation; normal range is indicated in parentheses. Data available for at least $90 \%$ of patients. ${ }^{*} P<0.05$, significantly different than the fibrinogen-PCC group;

${ }^{*} P=0.0001$, significantly different than the fibrinogen-PCC group. FFP, fresh frozen plasma; $n$, number of patients; PCC, prothrombin complex concentrate. 


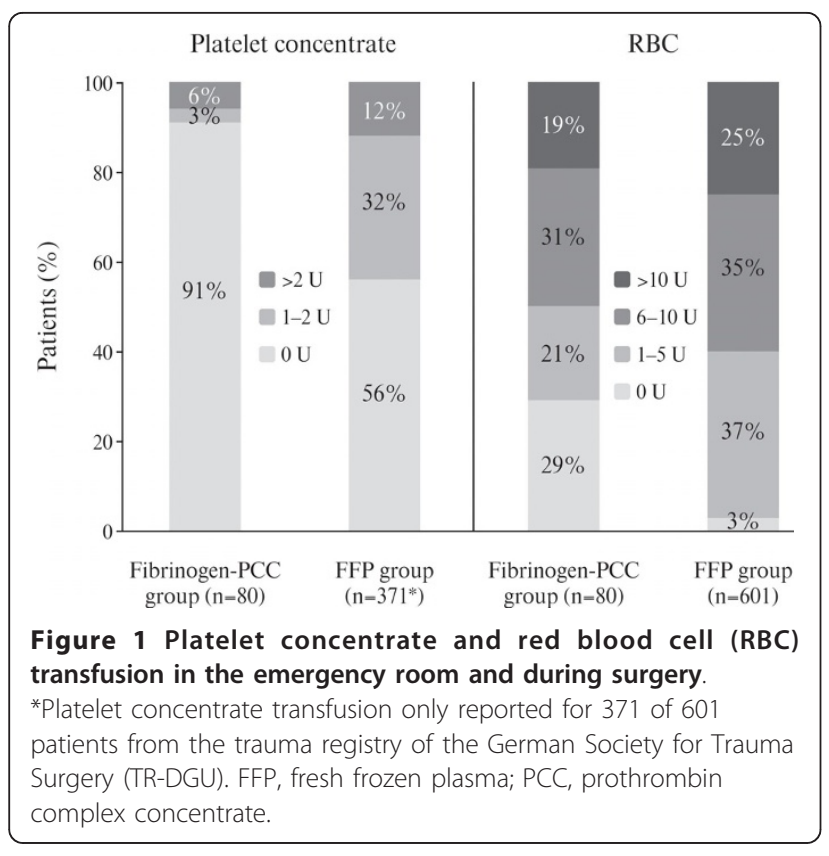

424 patients) and 3 units of FFP (IQR: 0, 6; range: 0, 80; data reported for 405 patients). No information is available on platelet concentrate transfusion in this group during the stay on the ICU. For the fibrinogen-PCC group, a complete set of transfusion data was available. During their stay at the ICU, these patients received a median dose of 2 units of RBC (IQR: 0, 3; range: 0,11 ), platelet concentrate was transfused in $9 \%$ of the patients during this time (the dose was 1 or 2 units). The patients also received a median dose of $6 \mathrm{~g}$ of fibrinogen concentrate (IQR: 3, 10; range: 0,22 ) and a median of 1,200 U of PCC (IQR: 0, 2,400; range: 0, 9,000).

For haemostatic therapy in the ER and during surgery, the median ratio of FFP:RBC in the FFP group was 1 (IQR: 0.7, 1.3; minimum 0.1, maximum 6.5); Figure 3 shows the ratios for all patients in the group. The same median value was observed in each of the four years included in the analysis (2005 to 2008). In the fibrinogen-PCC group, the median ratio of fibrinogen concentrate: $\mathrm{RBC}$ for coagulation therapy in the ER and during surgery was 0.9 (IQR: 0.7, 1.2), and the ratio of PCC (in hundreds of units):RBC was 1.6 (IQR: 0, 3); Figure 3 shows the distributions of fibrinogen concentrate:RBC and PCC:RBC ratios.

Data relating to subsequent outcomes were available for all patients. The median duration of postoperative intubation was 9.5 days (IQR: $3.5,14$ ) in the fibrinogenPCC group, significantly longer than the 7 days (IQR: 2, $16)$ in the FFP group $(P=0.005)$. Median length of stay (LOS) in the ICU, however, was comparable in the two groups: 14.5 days (IQR: $8.5,21$ ) in the fibrinogen-PCC group and 14 days (IQR: 6,23$)$ in the FFP group $(P=$ 0.95). In contrast, the median LOS in the hospital was significantly different between the two groups: 23 days (IQR: $14.5,40.5)$ in the fibrinogen-PCC group and 32 days (IQR: 20,49$)$ in the FFP group $(P=0.005)$. Mortality was $10.0 \%$ in the FFP group and $7.5 \%$ in the fibrinogen-PCC group $(P=0.69$, not significant).

\section{Discussion}

The present study compared TEM-guided haemostatic therapy using fibrinogen concentrate and PCC, with standard FFP-based therapy, in trauma patients. RBC transfusion was avoided in $29 \%$ of patients in the fibrinogen-PCC group, and these patients received no transfusion of any allogeneic blood products. In contrast, RBC transfusion was avoided in only $3 \%$ of patients in the FFP group. Transfusion of platelet concentrate was avoided in $91 \%$ of patients in the fibrinogen-PCC group, compared with $56 \%$ in the FFP group. In our trauma centre, TEM-guided haemostatic therapy with fibrinogen concentrate and PCC has been associated with a continuing decrease in the use of all types of allogeneic blood products.
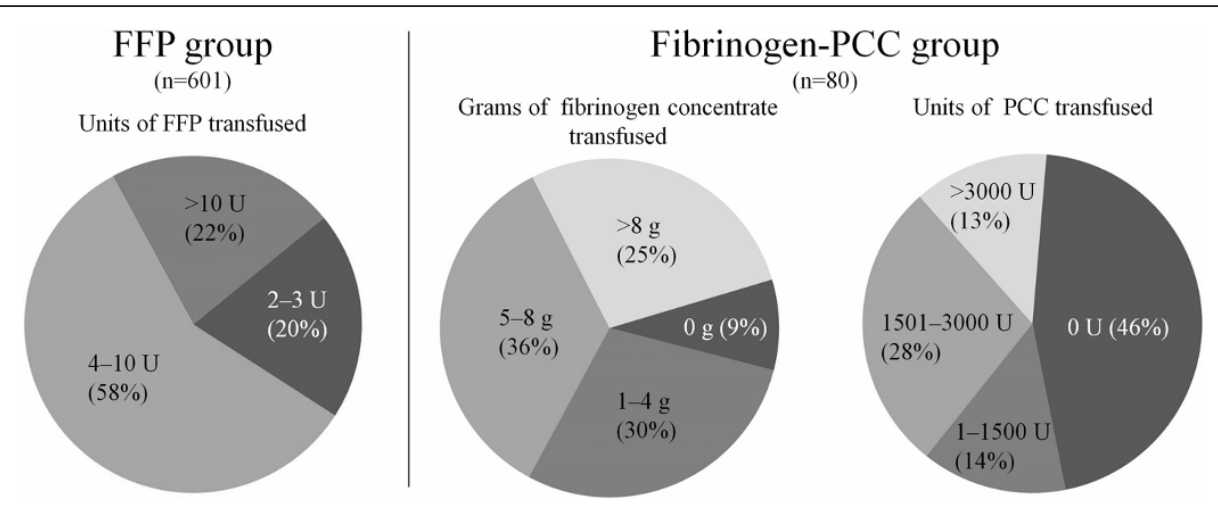

Figure 2 Percentage of patients receiving the indicated amount of haemostatic agent (FFP, fibrinogen concentrate, PCC) in the emergency room and during surgery. Percentage of patients in brackets. FFP, fresh frozen plasma; PCC, prothrombin complex concentrate. 


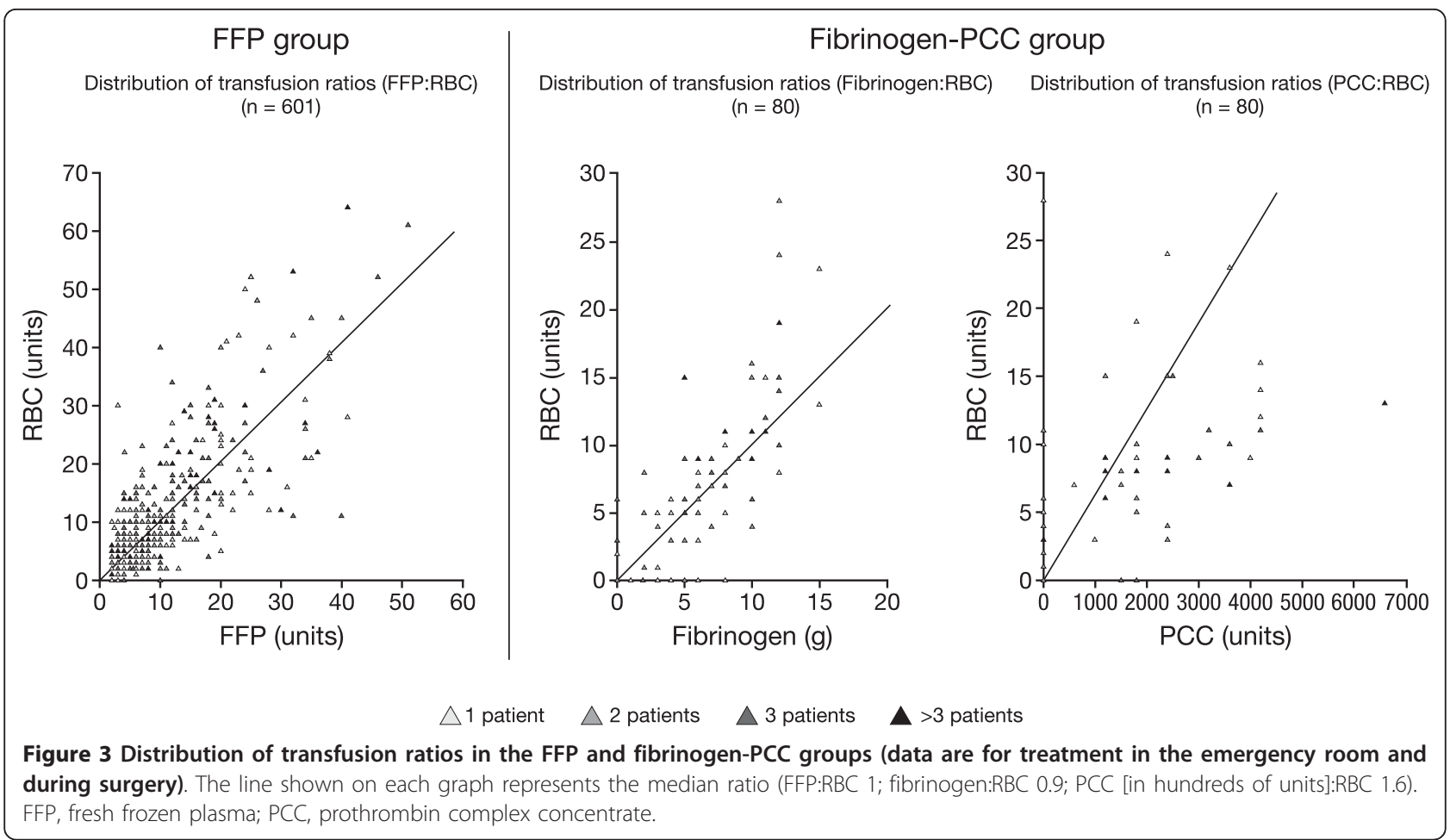

Minimising or avoiding exposure to allogeneic blood products is clearly desirable. The reasons for developing alternative treatments include intermittent supply shortages and public concern regarding the safety of allogeneic blood products $[20,21]$. Transfusion of FFP, for instance, carries the risk of transfusion-related lung injury, transfusion-associated circulatory overload, acute respiratory distress syndrome, transfusion-related immunomodulation and pathogen transmission [22-24]. Attempts to reduce FFP transfusion are complicated by the fact that small quantities of FFP are not effective in correcting coagulopathy $[25,26]$. Therefore, administration of FFP in larger amounts should be recommended, but high doses may have a dilutional effect on haematocrit, leading to an increase in RBC transfusion. In contrast, our study showed a reduction in $\mathrm{RBC}$ and platelet concentrate transfusion among patients treated with fibrinogen concentrate and PCCs. High levels of fibrinogen increase maximum clot firmness even in patients with a low platelet count, suggesting possible compensation for reduced platelet levels (it is hypothesised that an increased number of fibrin molecules binding a smaller number of platelets may be feasible without compromising clot integrity) $[13,14]$. The explanation for reduced $\mathrm{RBC}$ transfusion is more uncertain, but coagulation factor concentrates may provide faster cessation of bleeding and reduced haemodilution compared with allogeneic blood products. Due to their low volume of administration, coagulation factor concentrates are also likely to have a smaller effect on haematocrit. The use of TEM to diagnose coagulopathy may additionally help reduce $\mathrm{RBC}$ and platelet concentrate transfusion. There is increasing evidence of the usefulness of viscoelastic methods for diagnosing trauma-induced coagulopathy [12,27-29], and several reports have described a reduction in transfusion requirements following its introduction to treatment algorithms [30-32].

Our approach to managing coagulopathy in trauma patients focuses on the use of fibrinogen concentrate and PCC, which are quicker to administer than allogeneic blood products. Several groups have suggested that reducing the time to administer haemostatic therapy may improve patient outcomes [8-10]. Our group recently described an algorithm of goal-directed coagulation therapy with fibrinogen and PCC in major trauma patients [12], and in that study $52 \%$ of patients received the first dose of fibrinogen concentrate within the first hour, most of them within 30 minutes. In contrast, in a study published by Snyder et al., the first unit of FFP was typically administered at a median of 93 minutes after arrival at the ER [8]. Such delay may be related to the need for blood group matching, thawing and warming of FFP before administration (thawing and warming usually take about 30 minutes). It may be possible to address this delay, for example by storing thawed plasma for immediate application [33]. The use of predefined transfusion packages has also been described [34]. Most trauma centres use defined transfusion 
packages containing cooled $\mathrm{RBC}$ and frozen or thawed FFP. Unfortunately, thawing FFP in advance may have negative consequences, because unused thawed units must be discarded. To reduce apparent wastage, physicians may be tempted to overuse FFP. This tendency must be considered in the context of today's economic and administrative pressures, because the costs of blood products are high and often underestimated [35]. The time to infuse medication is another consideration. In general, it is recommended that one unit of FFP is administered over a period of about 30 minutes. In contrast, typical doses of fibrinogen concentrate and PCC may be administered in less than 10 minutes [16,36], and plasma levels of the coagulation factors administered rise rapidly after infusion.

This study was not designed to establish whether TEMguided haemostatic therapy with fibrinogen concentrate and PCC improves mortality. Large numbers of patients would be required to provide statistically robust evidence on mortality [37]. We nevertheless report an encouraging trend towards lower mortality in the fibrinogen-PCC group compared with the FFP group: $7.5 \%$ versus $10.0 \%$ $(P=0.69)$. One factor likely to affect survival is the speed of administration of haemostatic therapy - as discussed above, TEM-guided haemostatic therapy with fibrinogen concentrate and PCC may be advantageous from that point of view. The quantity of fibrinogen administered may also affect mortality rates. Stinger et al. reported correlations between the amount of fibrinogen administered and blood loss and survival in severely bleeding patients from the Iraq war [38]. Successful haemostatic therapy with fibrinogen concentrate has been described in other settings involving extensive surgery and blood loss (e.g., cardiovascular surgery) [39-41]. Successful use of PCC to treat acquired coagulopathy in the perioperative setting has previously been reported, albeit in limited numbers of patients $[11,12,42,43]$. Animal experiments have suggested that PCC may be more effective than FFP in the trauma setting [44], whereas Austrian guidelines recommend PCC administration in bleeding patients if clotting time measured by thrombelastography (TEG)/ TEM is prolonged [45]. In the present study, PCC was administered to treat bleeding when clotting time in the EXTEM assay was prolonged.

The study inclusion criteria aimed at minimise between-group differences in patient characteristics. The choice of $1 \mathrm{~g}$ fibrinogen/500 U PCC as inclusion criteria was based on practical therapy. The minimum amount of fibrinogen concentrate administered in clinical practice is $1 \mathrm{~g}$, and patients from the STC were eligible for inclusion in the study once they had received this dose. Similarly, the minimum dose of PCC was $500 \mathrm{U}$. We chose 2 units of FFP as the criterion for the comparator group because this dose should contain approximately
$1 \mathrm{~g}$ of fibrinogen [4], thus enabling comparison with the fibrinogen-PCC group.

The data analysis revealed some between-group differences in patient characteristics, and these are worthy of consideration. Although ISS, TRISS, RISC and AIS for abdomen and extremity were not significantly different, there was a significant trend towards more severe head and chest trauma in the FFP-group. Surprisingly, however, the score predicting massive transfusion (TASH) was higher in the fibrinogen-PCC group. Furthermore, it is difficult to estimate whether trauma-induced coagulopathy related to hypoperfusion was more pronounced in either of these two groups. On the one hand, blood pressure was significantly lower in the fibrinogen-PCC group, and base deficit was non-significantly lower in this group. On the other hand, both PT (expressed as a percentage) and platelet count were higher in the FFP group ( $P$ not significant for platelet count). Had hypoperfusion been more pronounced in the fibrinogen-PCC group, the significantly lower transfusion rates would appear even more encouraging.

The present study has several limitations. Data for the fibrinogen-PCC group were collected retrospectively from only one centre. TR-DGU data are collected via standardised forms from trauma centres throughout central Europe. Although only the main parameters of trauma management and patient outcome are reported and the collection of data was carefully checked, there may be some reporting bias. Furthermore, for some patients included in the study, the data were incomplete - particularly regarding platelet concentrate transfusion. It cannot be ruled out that some centres providing data to the TRDGU may be using TEM sporadically. As there are currently no publications on the use of TEM in these centres, the impact on our results is difficult to estimate. The present study did not evaluate any safety aspects, such as thromboembolic or infectious complications. The important difference observed in LOS in the hospital between the two groups, although encouraging, may be influenced by local patient management protocols. A prospective study would be needed to confirm which therapeutic approach offers the more favourable outcome.

\section{Conclusions}

In the present study, TEM-guided haemostatic therapy with fibrinogen concentrate and PCC reduced the exposure of trauma patients to allogeneic blood products. To improve current transfusion practice, the potential role of coagulation factor concentrates in achieving haemostasis rapidly among trauma patients must be considered.

\section{Key messages}

- In attempting to reduce transfusion of allogeneic blood products, new therapeutic options are being 
investigated for the management of bleeding in trauma patients.

- The present study compared transfusion of RBC and platelet concentrate in patients receiving either TEM-guided haemostatic therapy with fibrinogen concentrate and PCC, or standard FFP-based therapy.

- RBC transfusion was avoided in $29 \%$ of patients in the fibrinogen-PCC group, and these patients received no transfusion of any allogeneic blood products. In contrast, RBC transfusion was avoided in only $3 \%$ of patients in the FFP group.

- Transfusion of platelet concentrate was avoided in $91 \%$ of patients in the fibrinogen-PCC group, compared with $56 \%$ in the FFP group.

- TEM-guided haemostatic therapy with fibrinogen concentrate and PCC reduced the exposure of trauma patients to allogeneic blood products.

\begin{abstract}
Abbreviations
AIS: abbreviated injury score; ER: emergency room; FFP: fresh frozen plasma; IQR: interquartile range; ISS: injury severity scores; LOS: length of stay; PCC: prothrombin complex concentrate; PT: prothrombin time; RBC: red blood cells; RISC: revised injury severity classification score; STC: Salzburg Trauma Centre; TEM: thromboelastometry; TR-DGU: TraumaRegister DGU; TRISS: trauma injury severity score.

\section{Acknowledgements}

Editorial assistance was provided by Ken Sutor of Fishawack Communications Ltd. during late-stage development of this manuscript. Financial support for this assistance was provided by CSL Behring GmbH.
\end{abstract}

\begin{abstract}
Author details
${ }^{1}$ Ludwig Boltzmann Institute of Experimental and Clinical Traumatology, Donaueschingenstrasse 13, A-1200 Vienna, Austria. ${ }^{2}$ Department of Anaesthesiology and Intensive Care, AUVA Trauma Centre, Dr. Franz-RehrlPlatz 5, 5010 Salzburg, Austria. ${ }^{3}$ Institute for Research in Operative Medicine, University of Witten/Herdecke, Cologne-Merheim Medical Center, Ostmerheimer Strasse 200, 51109 Cologne, Germany. ${ }^{4}$ Department of Trauma and Orthopedic Surgery, University of Witten/Herdecke, CologneMerheim Medical Centre, Ostmerheimer Strasse 200, 51109 Cologne, Germany. ${ }^{5}$ Department of Commercial Operations Western Europe, CSL Behring UK, Hayworth House, Market Place, Haywards Heath, RH16 1DB, UK. ${ }^{6}$ Department of Anaesthesiology and Intensive Care, Salzburger Landeskliniken SALK, Müllner Hauptstrasse 48, A-5020 Salzburg, Austria. ${ }^{7}$ Department of Anaesthesiology and Intensive Care, University Hospital Marburg, Baldingerstrasse, 35033 Marburg, Germany. ${ }^{8}$ Department of Anaesthesiology and Intensive Care, Hannover Medical School, Carl-Neuberg Strasse 1, 30625 Hannover, Germany.
\end{abstract}

\section{Authors' contributions}

HS designed the study, contributed to acquiring the data in the STC, and wrote the manuscript. UN acquired the data from the TR-DGU, performed the statistical analysis and contributed to writing the manuscript. MM contributed to acquiring the data from the TR-DGU and to writing the manuscript. GH contributed to designing the study, analysing the data and writing the manuscript. FP, BS and CA acquired the data from the STC. AH, W and CJ contributed to writing the manuscript. CS contributed to designing the study, analysing the data, and writing the manuscript. All authors read and approved the final manuscript.

\section{Competing interests}

This study was performed without external funding. HS, CS and MM have received honoraria as speakers and research support from CSL Behring (manufacturer of fibrinogen concentrate and PCC) and Tem International $\mathrm{GmbH}$ (manufacturer of the TEM device). AH has received honoraria as speaker and research support from CSL Behring. GH is an employee of CSL Behring. All other authors declare that they have no competing interests.

Received: 27 July 2010 Revised: 11 December 2010

Accepted: 4 March 2011 Published: 4 March 2011

\section{References}

1. Brohi $K$, Singh J, Heron M, Coats T: Acute traumatic coagulopathy. J Trauma 2003, 54:1127-1130.

2. Rossaint R, Bouillon B, Cerny V, Coats TJ, Duranteau J, Fernandez-Mondejar E, Hunt BJ, Komadina R, Nardi G, Neugebauer E, Ozier Y, Riddez L, Schultz A, Stahel PF, Vincent JL, Spahn DR: Management of bleeding following major trauma: an updated European guideline. Crit Care 2010, 14:R52.

3. Holcomb JB, Jenkins D, Rhee P, Johannigman J, Mahoney P, Mehta S, Cox ED, Gehrke MJ, Beilman GJ, Schreiber M, Flaherty SF, Grathwohl KW, Spinella PC, Perkins JG, Beekley AC, McMullin NR, Park MS, Gonzalez EA, Wade CE, Dubick MA, Schwab CW, Moore FA, Champion HR, Hoyt DB, Hess JR: Damage control resuscitation: directly addressing the early coagulopathy of trauma. J Trauma 2007, 62:307-310.

4. Ketchum L, Hess JR, Hiippala S: Indications for early fresh frozen plasma, cryoprecipitate, and platelet transfusion in trauma. J Trauma 2006, 60: S51-58.

5. Borgman MA, Spinella PC, Perkins JG, Grathwohl KW, Repine T, Beekley AC, Sebesta J, Jenkins D, Wade CE, Holcomb JB: The ratio of blood products transfused affects mortality in patients receiving massive transfusions at a combat support hospital. J Trauma 2007, 63:805-813.

6. Maegele M, Lefering R, Paffrath T, Tjardes T, Simanski C, Bouillon B: Redblood-cell to plasma ratios transfused during massive transfusion are associated with mortality in severe multiple injury: a retrospective analysis from the Trauma Registry of the Deutsche Gesellschaft fur Unfallchirurgie. Vox Sang 2008, 95:112-119.

7. Teixeira PG, Inaba K, Shulman I, Salim A, Demetriades D, Brown C, Browder T, Green D, Rhee P: Impact of plasma transfusion in massively transfused trauma patients. J Trauma 2009, 66:693-697.

8. Snyder CW, Weinberg JA, McGwin G Jr, Melton SM, George RL, Reiff DA Cross JM, Hubbard-Brown J, Rue LW, Kerby JD: The relationship of blood product ratio to mortality: survival benefit or survival bias? J Trauma 2009, 66:358-362.

9. Riskin DJ, Tsai TC, Riskin L, Hernandez-Boussard T, Purtill M, Maggio PM, Spain DA, Brundage SI: Massive transfusion protocols: the role of aggressive resuscitation versus product ratio in mortality reduction. J Am Coll Surg 2009, 209:198-205.

10. Gonzalez EA, Moore FA, Holcomb JB, Miller CC, Kozar RA, Todd SR, Cocanour CS, Balldin BC, McKinley BA: Fresh frozen plasma should be given earlier to patients requiring massive transfusion. J Trauma 2007, 62:112-119.

11. Schöchl H, Forster L, Woidke R, Solomon C, Voelckel W: Use of rotation thromboelastometry (ROTEM) to achieve successful treatment of polytrauma with fibrinogen concentrate and prothrombin complex concentrate. Anaesthesia 2010, 65:199-203.

12. Schöchl H, Nienaber U, Hofer G, Voelckel W, Jambor C, Scharbert G, KozekLangenecker S, Solomon C: Goal-directed coagulation management of major trauma patients using thromboelastometry (ROTEM(R))-guided administration of fibrinogen concentrate and prothrombin complex concentrate. Crit Care 2010, 14:R55.

13. Lang T, Johanning K, Metzler H, Piepenbrock S, Solomon C, Rahe-Meyer N Tanaka KA: The effects of fibrinogen levels on thromboelastometric variables in the presence of thrombocytopenia. Anesth Analg 2009, 108:751-758.

14. Velik-Salchner C, Haas T, Innerhofer P, Streif W, Nussbaumer W, Klingler A, Klima G, Martinowitz U, Fries D: The effect of fibrinogen concentrate on thrombocytopenia. J Thromb Haemost 2007, 5:1019-1025.

15. Rivera J, Lozano ML, Navarro-Nunez L, Vicente V: Platelet receptors and signaling in the dynamics of thrombus formation. Haematologica 2009, 94:700-711.

16. Solomon C, Pichlmaier U, Schoechl H, Hagl C, Raymondos K, Scheinichen D, Koppert W, Rahe-Meyer N: Recovery of fibrinogen after administration of fibrinogen concentrate to patients with severe bleeding after cardiopulmonary bypass surgery. Br J Anaesth 2010, 104:555-562. 
17. Dargaud Y, Desmurs-Clavel H, Marin S, Bordet JC, Poplavsky JL, Negrier C: Comparison of the capacities of two prothrombin complex concentrates to restore thrombin generation in plasma from orally anticoagulated patients: an in vitro study. J Thromb Haemost 2008, 6:962-968.

18. Lefering R: Development and validation of the revised injury severity classification score for severely injured patients. Eur J Trauma Emerg Surg 2009, 35:437-447.

19. Davis EG, MacKenzie EJ, Sacco WJ, Bain LW Jr, Buckman RF Jr, Champion HR, Lees PS: A new "TRISS-like" probability of survival model for intubated trauma patients. J Trauma 2003, 55:53-61.

20. Nouwairi NS: The risks of blood transfusions and the shortage of supply leads to the quest for blood substitutes. AANA J 2004, 72:359-364.

21. Spahn DR: Blood substitutes. Crit Care 1999, 3:R91-92.

22. Dara SI, Rana R, Afessa B, Moore SB, Gajic O: Fresh frozen plasma transfusion in critically ill medical patients with coagulopathy. Crit Care Med 2005, 33:2667-2671.

23. Sarani B, Dunkman WJ, Dean L, Sonnad S, Rohrbach Jl, Gracias VH: Transfusion of fresh frozen plasma in critically ill surgical patients is associated with an increased risk of infection. Crit Care Med 2008, 36:1114-1118.

24. Serious Hazards Of Transfusion annual report 2007. [http://www.shotuk. org/wp-content/uploads/2010/03/SHOT-Report-2007.pdf].

25. Armand R, Hess JR: Treating coagulopathy in trauma patients. Transfus Med Rev 2003, 17:223-231.

26. Chowdhury P, Saayman AG, Paulus U, Findlay GP, Collins PW: Efficacy of standard dose and $30 \mathrm{ml} / \mathrm{kg}$ fresh frozen plasma in correcting laboratory parameters of haemostasis in critically ill patients. $\mathrm{Br} J$ Haematol 2004, 125:69-73.

27. Rugeri L, Levrat A, David JS, Delecroix E, Floccard B, Gros A, Allaouchiche B, Negrier C: Diagnosis of early coagulation abnormalities in trauma patients by rotation thrombelastography. J Thromb Haemost 2007 5:289-295.

28. Schöchl H, Frietsch T, Pavelka M, Jambor C: Hyperfibrinolysis after major trauma: differential diagnosis of lysis patterns and prognostic value of thrombelastometry. J Trauma 2009, 67:125-131.

29. Plotkin AJ, Wade CE, Jenkins DH, Smith KA, Noe JC, Park MS, Perkins JG, Holcomb JB: A reduction in clot formation rate and strength assessed by thrombelastography is indicative of transfusion requirements in patients with penetrating injuries. J Trauma 2008, 64:S64-68.

30. Spalding GJ, Hartrumpf M, Sierig T, Oesberg N, Kirschke CG, Albes JM: Cost reduction of perioperative coagulation management in cardiac surgery: value of "bedside" thrombelastography (ROTEM). Eur J Cardiothorac Surg 2007, 31:1052-1057.

31. Theusinger OM, Spahn DR, Ganter MT: Transfusion in trauma: why and how should we change our current practice? Curr Opin Anaesthesiol 2009, 22:305-312.

32. Girdauskas E, Kempfert J, Kuntze T, Borger MA, Enders J, Fassl J, Falk V, Mohr FV: Thromboelastometrically-guided transfusion protocol during aortic surgery with circulatory arrest: a prospective, randomized trial. J Thorac Cardiovasc Surg 2010, 140:1117-1124.

33. Nascimento B, Callum J, Rubenfeld G, Neto JB, Lin Y, Rizoli S: Clinical review: fresh frozen plasma in massive bleedings - more questions than answers. Crit Care 2010, 14:202.

34. Johansson PI, Bochsen L, Stensballe J, Secher NH: Transfusion packages for massively bleeding patients: the effect on clot formation and stability as evaluated by Thrombelastograph (TEG). Transfus Apher Sci 2008, 39:3-8.

35. Shander A, Hofmann A, Ozawa S, Theusinger OM, Gombotz H, Spahn DR: Activity-based costs of blood transfusions in surgical patients at four hospitals. Transfusion 2010, 50:753-765.

36. Pabinger I, Tiede A, Kalina U, Knaub S, Germann R, Ostermann H, Beriplex P/N Anticoagulation Reversal Study Group: Impact of infusion speed on the safety and effectiveness of prothrombin complex concentrate: a prospective clinical trial of emergency anticoagulation reversal. Ann Hematol 2010, 89:309-316.

37. Hauser CJ, Boffard K, Dutton R, Bernard GR, Croce MA, Holcomb JB, Leppaniemi A, Parr M, Vincent JL, Tortella BJ, Dimsits J, Bouillon B, CONTROL Study Group: Results of the CONTROL trial: efficacy and safety of recombinant activated Factor VII in the management of refractory traumatic hemorrhage. J Trauma 2010, 69:489-500.

38. Stinger HK, Spinella PC, Perkins JG, Grathwohl KW, Salinas J, Martini WZ, Hess JR, Dubick MA, Simon CD, Beekley AC, Wolf SE, Wade CE, Holcomb JB:
The ratio of fibrinogen to red cells transfused affects survival in casualties receiving massive transfusions at an army combat support hospital. J Trauma 2008, 64:S79-85.

39. Fenger-Eriksen $C$, Jensen TM, Kristensen BS, Jensen KM, Tonnesen E, Ingerslev J, Sorensen B: Fibrinogen substitution improves whole blood clot firmness after dilution with hydroxyethyl starch in bleeding patients undergoing radical cystectomy: a randomized, placebo-controlled clinical trial. J Thromb Haemost 2009, 7:795-802.

40. Rahe-Meyer N, Solomon C, Winterhalter M, Piepenbrock S, Tanaka K, Haverich A, Pichlmaier M: Thromboelastometry-guided administration of fibrinogen concentrate for the treatment of excessive intraoperative bleeding in thoracoabdominal aortic aneurysm surgery. $J$ Thorac Cardiovasc Surg 2009, 138:694-702.

41. Rahe-Meyer N, Pichlmaier M, Haverich A, Solomon C, Winterhalter M, Piepenbrock S, Tanaka KA: Bleeding management with fibrinogen concentrate targeting a high-normal plasma fibrinogen level: a pilot study. Br J Anaesth 2009, 102:785-792.

42. Bruce D, Nokes TJ: Prothrombin complex concentrate (Beriplex $P / N$ ) in severe bleeding: experience in a large tertiary hospital. Crit Care 2008, 12 R105.

43. Schick KS, Fertmann JM, Jauch KW, Hoffmann JN: Prothrombin complex concentrate in surgical patients: retrospective evaluation of vitamin $\mathrm{K}$ antagonist reversal and treatment of severe bleeding. Crit Care 2009, 13: R191.

44. Dickneite G, Pragst I: Prothrombin complex concentrate vs fresh frozen plasma for reversal of dilutional coagulopathy in a porcine trauma model. Br J Anaesth 2009, 102:345-354.

45. Fries $D$, Innerhofer $P$, Perger $P$, Gütl $M$, Heil $S$, Hofmann $N$, Kneifl W, Neuner L, Pernerstorfer T, Pfanner G, Schöchl H, Ziegler B, Köblinger C, Kozek-Langenecker S: [Coagulation management in trauma-related massive bleeding. Recommendations of the Task Force for Coagulation (AGPG) of the Austrian Society of Anesthesiology, Resuscitation and Intensive Care Medicine (OGARI)]. Anasthesiol Intensivmed Notfallmed schmerzther 2010, 45:552-561.

doi:10.1186/cc10078

Cite this article as: Schöchl et al:: Transfusion in trauma:

thromboelastometry-guided coagulation factor concentrate-based therapy versus standard fresh frozen plasma-based therapy. Critical Care 2011 15:R83.

\section{Submit your next manuscript to BioMed Central and take full advantage of:}

- Convenient online submission

- Thorough peer review

- No space constraints or color figure charges

- Immediate publication on acceptance

- Inclusion in PubMed, CAS, Scopus and Google Scholar

- Research which is freely available for redistribution

Submit your manuscript at www.biomedcentral.com/submit
C Biomed Central 